\title{
Repair of subsidence damage: An insurer's perspective
}

Received (in revised form): 1st April, 2005

\begin{abstract}
Nick Deakin CEng, BSc (Hons), MICE, FCILA, MCMI
is a chartered engineer and chartered loss adjuster employed within Royal and Sun Alliance's (R\&SA) head office 'Technical Claims' team and responsible for the management of R\&SA's subsidence programme. Nick graduated from City University in 1980 and, after working in the civil engineering industry, qualified as a chartered engineer in 1985, joining loss adjusters GAB Robins in 1987 as a specialist property adjuster working in the West Country. Having qualified as a chartered loss adjuster in 1995, Nick applied his engineering and construction knowledge to the investigation of subsidence damage, as well as complex commercial fire and engineering claims. Having joined R\&SA in 1999 as part of a newly established, in-house engineering team, Nick has worked on the re-engineering of subsidence claims handling in the organisation which has resulted in the establishment of a dedicated subsidence supply chain and an in-house engineering and adjusting team. Nick has been a member of the Chartered Management Institute since 2003.
\end{abstract}

\section{Abstract}

The objective of this paper is to provide an insight into the appraisal, investigation and management of insurance claims for subsidence damage to domestic properties. The paper will consider typical insurance policy wording, explore the causes of cracking to domestic properties in the UK and consider what constitutes subsidence damage. Using case study examples, the paper reviews current techniques used to investigate and repair subsidence damage and how a major insurer manages high volumes of claims. Making reference to the wider market and business environment, the paper examines the changing roles of the insurer, loss adjuster, engineer and building repairer in the investigation and repair process. The paper concludes by considering how innovation will help to manage the increase in claims volume predicted to arise as a result of climate change.

\section{Keywords:}

subsidence, insurance, ground investigation, arboriculture, clay shrinkage, cracking

\section{INTRODUCTION}

The handling of insurance claims associated with subsidence damage involves a mix of disciplines including building surveying, structural engineering, geotechnical engineering, arboriculture and law, as well as good insurance practice and, most importantly, an understanding of customer care and communication.

Nick Deakin

Royal and Sun Alliance West Gate, Colston Avenue Bristol BS1 4SY, UK

Tel: +44 (o)117 9937196

Fax: + 44 (0)1179937198

E-mail: nick.deakin@uk.royalsun.com

Prior to 1971 insurance cover was not provided for subsidence damage to domestic properties in the UK. That is not to say that subsidence damage did not occur to properties before that date; however, since 1971 there has been a measured increase in the volume and value of subsidence claims that have occurred in the UK. 


\section{Annual subsidence costs are significant}

\section{Claims costs surge during hot, dry summers}

Data from the Association of British Insurers (ABI) (Datamonitor, 2004) reports that in 200354,100 subsidence claims were made at a total estimated cost of $£ 390 \mathrm{~m}$. Figures $1 \mathrm{a}$ and $1 \mathrm{~b}$ illustrate the trends in claims volumes and costs through the summer and autumn of 2003. The trend shows the impact of hot dry weather creating a claims surge (or 'event').

Clearly, sitting behind this expenditure is a significant financial issue for insurance companies, a cause of anxiety for householders and an opportunity for a wide range of loss adjusting, contracting and consultant services in the construction industry. It can be argued that the increasing number of claims also reflects the greater awareness in the property market of the risks of subsidence damage and the impact subsidence can have on the saleability of a property. For example, this greater awareness means that a purchase survey will be more likely to highlight cracking in a

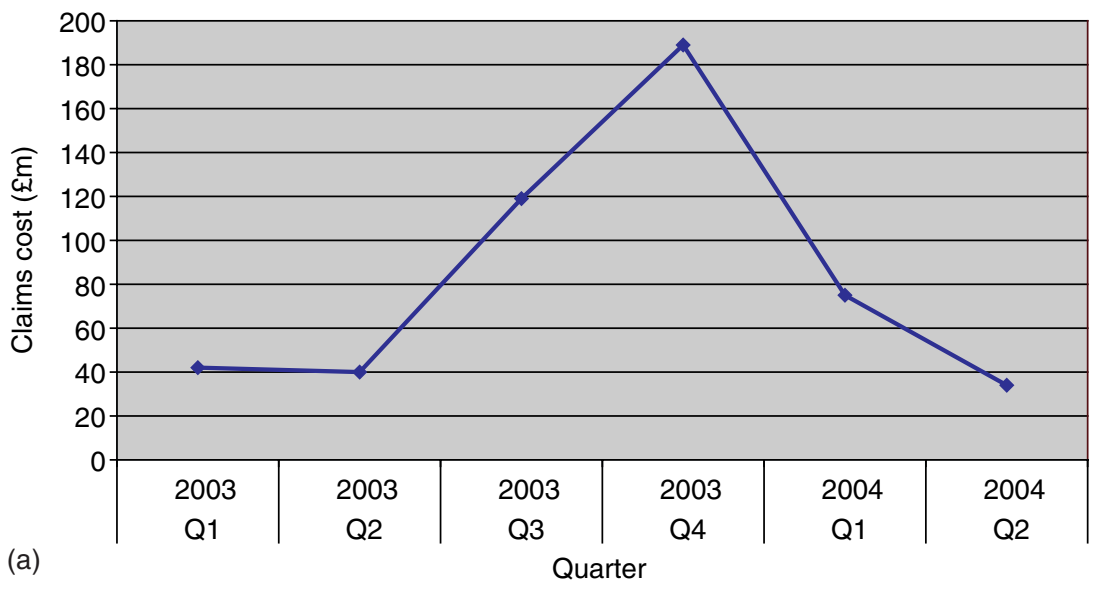

Source: Datamonitor (2004)

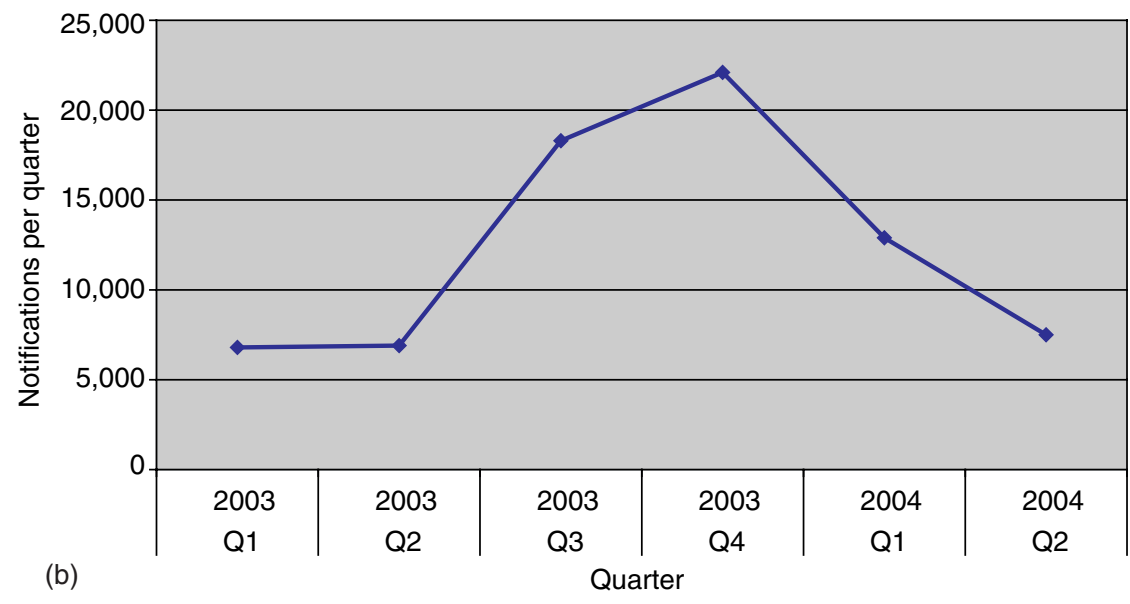

Source: Datamonitor (2004)

Figure 1: UK subsidence claims 2003-2004: (a) quarterly costs; (b) quarterly volume of instructions 
Over 50 per cent of notified claims are declined property and consequently make a householder more likely to notify their insurance company.

It is also significant that during a 'non-event' year between 50-60 per cent of subsidence claims notified to insurers are declined after investigation as the cracks to the house are found to be of no significance, or due to some cause other then subsidence.

When claims are accepted as subsidence damage they are increasingly likely to be investigated by loss adjusters or engineers employed directly by the insurer and repaired by term contractors appointed by the insurer. Consequently, the emphasis is on resolving the claim and repairing the building in the shortest possible time and as economically as possible.

\section{WHAT IS SUBSIDENCE?}

It is now generally accepted that subsidence is the vertical, downward movement of a building foundation caused by loss of support of the site beneath that foundation (see Figure 2). This is commonly associated with a change in the volume of the subsoil (eg shrinkage of clay), or loss of strength (eg softening by leaking drains), the cause of which occurs as a direct result of an external factor (such as trees or damaged drains).

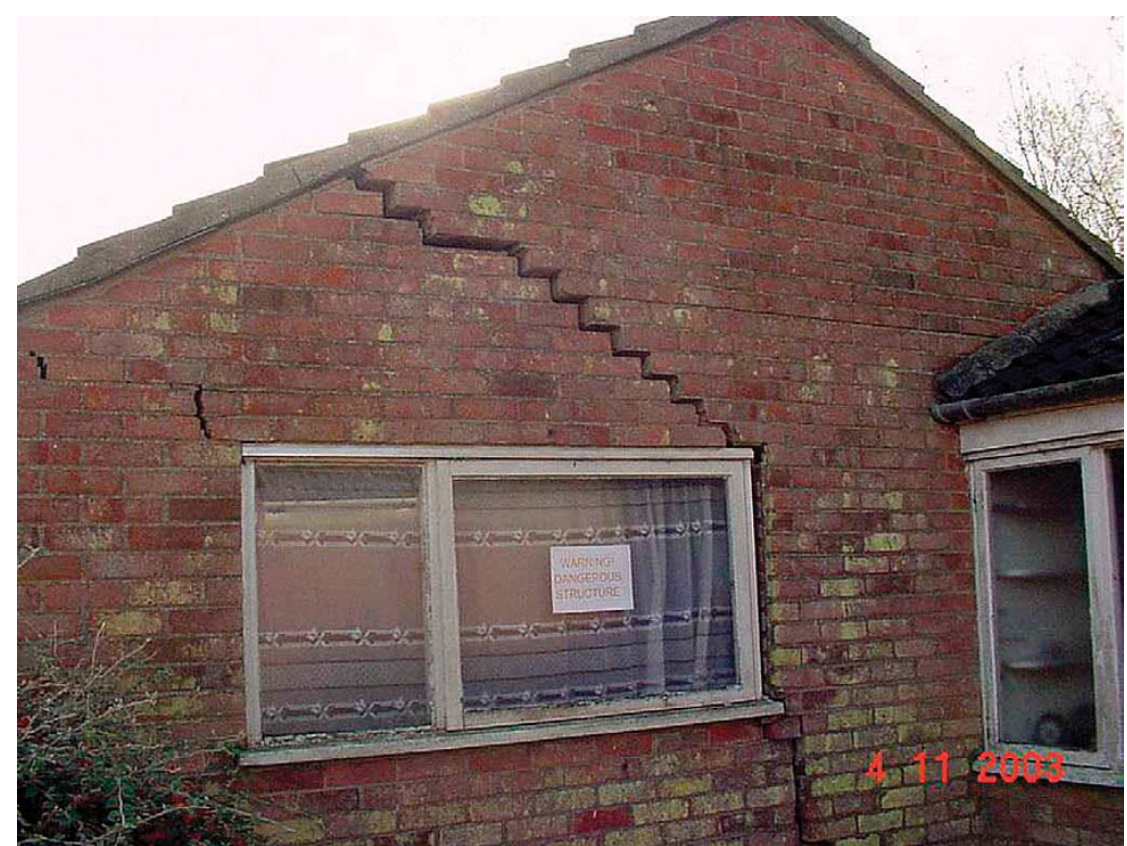

Figure 2: Severe category subsidence crack

\section{WHAT POLICY COVER IS PROVIDED?}

Typical policy cover provided in the UK household insurance market is for 'subsidence or heave of the land on which the buildings stand or of land belonging to the buildings or landslip' (R\&SA, 2004). Associated with this definition are three important aspects, however, as detailed below. 
Insurance cover has specific exclusions
Claims can be settled by repair or cash

\section{Definition of buildings}

Typically, the definition of buildings will include the main dwelling, conservatories, garages and outbuildings, patios, terraces, driveways, footpaths, tennis courts, swimming pools, walls, fences, gates and hedges. But subsidence cover does not apply directly to all these aspects. Typically, cover is restricted to the main dwelling, garages and outbuildings, but will extend to patios and driveways etc only if they are damaged at the same time and by the same cause as the main dwelling. Put simply, subsidence damage to a boundary wall or driveway on its own normally will not be covered.

\section{Subsidence cover exclusions}

Typical exclusions to subsidence cover include the following.

- 'Loss or damage from solid floors moving unless the foundations of the outside walls of the home are damaged by the same cause and at the same time.' This is intended to exclude cracking or settlement of poorly constructed concrete slabs where founded on poorly compacted fill.

- 'Loss or damage caused by the settlement and bedding down of new structures.' New buildings can crack early on in their life simply due to bedding down and load distribution on newly constructed foundations and underlying subsoils.

- 'Loss or damage caused by the coast (coastal erosion) or a river bank being eroded away.' There are many coastal sites in the UK, which are gradually being eroded away (to the extent that whole villages have disappeared on some stretches of the east coast).

- 'Loss or damage by or from any demolition, alteration or repair to the structure of the home.' For example, removal of load-bearing walls and introduction of load-bearing columns that impose excessive loads may cause foundation settlement and cracking to the property.

- 'Loss or damage caused by poor workmanship, poor design or faulty materials.' For example, construction of a new extension with improperly designed foundations may give rise to subsidence damage. In such a case the householder may have a right of action against the designer or builder employed. For example, a conservatory built directly off a patio.

\section{The basis of the claims settlement}

Most household insurance policies will deal with 'the cost of repair or replacing the damaged parts of the buildings including fees and related costs'. If a building is in a poor state of repair, insurers may not deal with the full reinstatement cost but will make deductions for wear and tear. There also may be penalties if the building is not insured for the full rebuilding cost. If the repairs are not carried out the policy may then only cover the reduction in market value caused by the damage (but will not exceed what it would have cost to repair). In addition, a policy excess may apply which is typically $£ 1,000$ for subsidence damage. The most an insurer will pay is obviously the sum insured, and this will include the cost 


\section{Insurance contracts have conditions}

of demolition, rebuilding to modern standards, professional fees, building regulations and party wall costs.

There are basic principles that apply to all insurance contracts. Typically, these are defined in the policy conditions, for example:

- Taking reasonable steps to prevent damage.

- Disclosing 'material facts' about the property, such as the state of repair, alterations to the property, a change in the sum insured, a change in the use of the building, or previous subsidence damage.

- Change in ownership: a policyholder has to have 'insurable interest' in the property to be able to benefit from a claim.

- In addition, the premiums have to have been paid and the claim has to be honestly presented.

As all subsidence claims have a degree of technical complexity and high potential cost attached to them, insurers will invariably appoint a loss adjuster or experienced subsidence expert to investigate and confirm both the cause of damage and that all insurance aspects are in order before accepting liability for the rectification work.

\section{WHAT ARE THE COMMON CAUSES OF SUBSIDENCE, LANDSLIP OR HEAVE?}

There are two main causes of subsidence damage — trees and drains. In addition, there are less common causes such as mining subsidence, failure of fill or made ground, lack of bearing capacity (peat), swallow holes etc. As policy cover is also extended to insure against landslip and heave, the management of subsidence claims will also encompass investigation and remedial works associated with these two perils.

\section{Trees}

In a normal year (ie one unaffected by drought) between $15-20$ per cent of

Trees in clay soils are a significant risk

\footnotetext{
Shrinkage potential of clay can vary
}

all notified claims have damage triggered by the effects of trees or vegetation on shrinkable clay soils. Clay soils would be expected subsidence is concerned are susceptible to volume change occurring as shrinkage when moisture is extracted from the soil and swelling when soil moisture is increased. The potential for a soil to shrink or swell is categorised by the Atterburg Limit of the soil. Atterburg was a Swedish agricultural scientist who established a standard classification of cohesive soils (eg clays) in 1913, which is still used today.

Clay can be moulded. If someone takes a sample in their hand and moulds it this can be seen and felt. If water is added and the moisture content increased during remoulding the sample becomes more and more plastic (soft and mouldable) and eventually behaves as a liquid.

- The water content at which clay moves from plastic to liquid is the liquid limit (LL). generally to have good load-bearing characteristics but critically as far as 
- The water content at which the soil ceases being plastic and becomes friable or brittle is the plastic limit (PL).

These two values of water content express the shear strength of the material under different conditions. The numerical difference between the LL and PL is called the plasticity index (PI). The basic classification of soils related to the PI is as follows

- PI between 10 and 20

- PI between 20 and 40

- PI $>40$
Low shrinkage potential

Medium shrinkage potential

High shrinkage potential

Therefore, soils with a higher PI are considered more likely to be affected by shrinking and swelling. The moisture content, when compared and contrasted with the LL and PL, is used to determine the desiccation state of the clay.

The significance of trees and vegetation as a cause of subsidence in clay soils is that root systems are capable of removing vast quantities of moisture from the soil, particularly during hot, dry spells of weather in the late summer and autumn. This situation directly causes drying and shrinkage of clay soils, to a state of desiccation in extreme cases, and consequently subsidence and cracking.

The potential for any tree to extract moisture is dependent upon the

Influence of trees varies with species and distance species and size of the tree. Research has been carried out by Kew Gardens and is published in the Institution of Structural Engineers' (ISE) publication Subsidence of Low Rise Buildings (ISE, 2000). This publication gives a table of guidelines as to the influencing distances of trees from properties based upon statistical evidence gathered by the Kew Gardens survey. An extract of the table is shown in Figure 3.

Distance from tree to building beyond which the tree is unlikely to be relevant

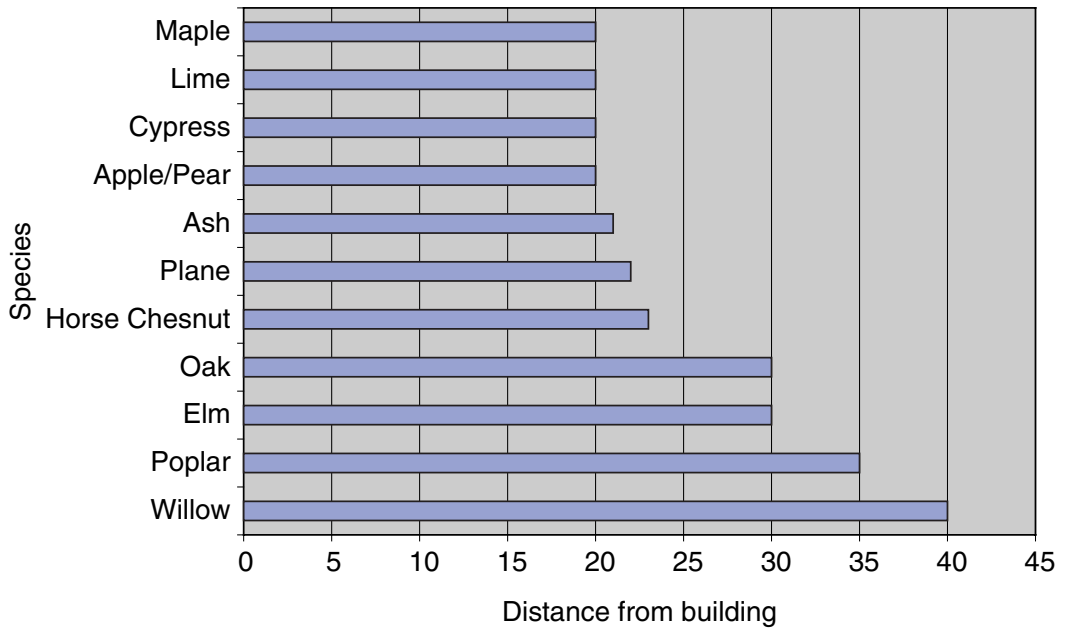

Figure 3: Trees - Safe distances, extract from ISE (2000) Table 6.3 


\section{Council owned trees create complex issues}

\section{Councils' liabilities have been tested in the courts}

\section{Leaking drains are a common cause}

The most contentious impact of trees on properties can be seen in the London boroughs where avenues of lime and plane trees were planted in the late 19th and early 20th centuries. These trees, belonging to the local authorities, are now mature and if left untended can grow to over $20-30 \mathrm{~m}$ in height. Although many are subject to rigorous management regimes, many of these street trees create a considerable risk of clay shrinkage related subsidence to vulnerable Edwardian and Victorian properties. Typically, these properties are likely to have shallow foundation depths, large window and door openings, and poor structural robustness to resist structural movement.

When these trees are implicated in damage and a request is presented to the responsible local authority for their removal there is understandably reluctance to condemn the trees outright and to fell them. Such trees may have high amenity value and, in some cases, historical and aesthetic qualities that would have attracted people to move into the area in the first place. Therefore, there is a careful balance to be drawn between maintaining such high-risk trees and avoiding or reducing the incidence of damage.

Over the years the courts have established that a local authority will have liability for damage that occurs to properties due to the effect of trees under their control. A series of high-profile legal cases have consistently decided against councils and in favour of householders (and their insurers). The most recent and significant case has been Loftus-Brigham $v$ Ealing Borough Council (October 2003). A list of key legal cases is attached at the end of this paper.

As recently as March 2005 Ealing Borough Council, the unsuccessful defendants in the Loftus-Brigham case, announced a wholesale review of 3,500 street trees in the borough.

The issue of street trees has to be addressed by local authorities, resident groups and insurers. These groups must recognise not only the risks to properties but also acknowledge the legal situation, creating a policy that respects the important aesthetic and environmental aspects of the city tree-scape. The obvious answer is a gradual renewal of the street tree scene, replacing those trees that represent the greatest risk with lowerrisk species.

While urban street trees create the high-profile cases there are other incidents of damage attributed to more modest species. In particular, fastgrowing trees such as leylandii and eucalyptus are popular with gardeners but notorious for causing problems, particularly when planted too close to properties often as screening vegetation.

\section{Drains}

In a normal, non-drought year, leaking drains are a factor in 25-30 per cent of all notified subsidence claims. The direct effect of a leaking gulley or fractured drainage run is for escaping water to soften soils or in extreme cases wash out material and cause voiding. The resultant loss of subsoil strength causes foundations to settle under working loads causing cracking to the superstructure. 
Landslip cover is provided in most policies
Drains are difficult for householders to maintain, being literally out of sight and out of mind. Problems will only become apparent when foul smells are noticed, or blockages or cracking to buildings occurs. But by that time the damage has been done.

\section{Mining subsidence}

Mining subsidence is relatively rare; however, when it does occur the results can be spectacular and difficult to remedy. Between the 18th and 20th century many industrial centres across the UK were heavily mined for coal and minerals. Many older mine workings were abandoned without accurate records and subsequent developments may not have taken the presence of workings into account. More recent workings have been managed under the jurisdiction of British Coal and responsibilities for consequent coal mining subsidence are strictly defined under the Coal Act.

Other examples of non-coal mining related damage are given below.

- In Coombe Down in Bath approximately 1,000 houses have been built over 18th century 'pillar and stall' workings used to extract limestone for local houses. In places the mine roof is less than $5 \mathrm{~m}$ below ground level and represents a considerable risk. The government is presently financing a major stabilisation scheme.

- All Cornish tin mines now have been abandoned and there have been numerous examples of uncharted mine shafts suddenly collapsing.

\section{Swallow holes}

Swallow holes are a feature found in chalk and gypsum deposits otherwise known as solution cavities. There are records of claims arising in the south-east of England and Yorkshire. When such claims do arise they are difficult to remedy because the swallow holes can cover a wide area and be difficult to stabilise.

\section{Landslip}

The legal case of Oddy v Phoenix Assurance Co (1965) provides a useful definition of a landslip as 'a rapid downward movement under the influence of gravity of a mass of rock or earth on a slope'. Consequently, there are many situations where landslip might happen, ranging from local slippage of surface material, say fill placed on a slope, to more complex geological events affecting a large area. As far as insurance cover is concerned, the Insurance Ombudsman more recently has taken the legal definition of landslip as applying to the sudden movement of earth occurring behind a failed retaining wall. The Ombudsman referred to the soil behind the retaining wall as being in a 'suspended state of landslip'. Damage relating to failed retaining walls should be treated with caution, however, as the failure of the retaining wall itself may have resulted from inadequate construction of the walls (see below). 
Not all retaining wall failures are insured

\section{Tree removal can present a heave risk}

\section{Retaining walls}

Many cities are built in steep, hilly areas and sites often have been levelled on a 'cut and fill' basis to build upon. These sites often require retaining walls to create terraces and accommodate variation in levels. Retaining walls inevitably require an element of structural design to support the weight of retained earth behind the wall and the imposed loads of driveways, paths, traffic or even the house itself.

There are many types and designs of retaining wall, ranging from reinforced concrete cantilever construction to massive stone walls. Failure of walls can occur for a variety of reasons including a build-up of ground water pressure, an increase in the imposed load behind the wall (by building works, for example) or removal of support at the toe of the wall.

Invariably the cost of reconstruction can be very high as it may involve specialist stabilisation techniques or complex temporary works. While insurance policies will respond where retaining wall failure has directly damaged the main house and repair is needed to stabilise the house, the failure of a retaining wall due to its age or poor design is often uninsured.

\section{Heave}

In simple terms, heave is the opposite of subsidence damage. The risk is usually associated with the removal of trees in clay soils causing the soil to expand and swell upwards. There have been cases where large-scale clearance of heavily wooded areas has occurred and houses have been built on desiccated subsoils without adequate protection to foundations against heave.

Other cases arise where large trees growing close to a house have died or have been removed. Incidents of heave are very rare and as a rule of thumb the risk only arises where large trees older than the property are removed. Empirical calculations can be carried out to evaluate heave risk associated with tree removal allowing assessment of the likelihood of damage.

\section{WHAT OTHER CRACKING IS MISTAKEN FOR SUBSIDENCE?}

Between 50-60 per cent of claims notified as subsidence damage are subsequently found to be building damage that has occurred due to other causes. Buildings crack for a wide range of reasons other than foundation movement. These cracks are symptoms of various problems associated with the design and construction of domestic properties, including materials selection and structural detailing. Therefore, when appraising building damage the surveyor or engineer must adopt a holistic approach, have an open mind and eliminate other possible causes before embarking on further investigations into possible subsidence damage.

\section{Poor structural detailing}

Domestic housing stock in the UK offers an infinite variety of sizes, shapes and materials and houses have been extended and altered in a 
Poor building design can cause cracking
Poor choice of materials can cause cracking
Insurance policies are not maintenance contracts variety of fashions. Following are a few examples of poor structural detailing resulting in masonry fractures.

- Gable end walls being provided with insufficient restraint ties at roof level resulting in lateral movement and horizontal cracking in the wall panel.

- Roof rafters being inadequately tied at their feet resulting in roof spread, which in some cases can cause lateral movement of the masonry at eaves level.

- First floor masonry panels being provided with inadequate support resulting in deflection of first floor joists and cracking to internal panels.

- Window units incorporating load-bearing mullions being replaced by poor-quality UPVC units with no load-bearing capacity, resulting in deflection and cracking of the masonry above.

- Opening up of ground floor living space by removing load-bearing walls without adequate provision of load-bearing beams at first floor level.

\section{Inability to accommodate temperature change}

All building materials undergo movement due to variations in temperature and this varies according to the materials' coefficient of expansion. If a wall is fully restrained along its edges it cannot expand and contract and cracking will occur.

\section{Movement due to a change in moisture content}

The majority of building materials (except metals, for example) are susceptible to dimensional change due to changes in their moisture content. Kiln-dried fresh bricks or concrete blocks will be at the greatest risk of moisture movement with long-term risk arising from absorption (where water molecules bond to the material molecules).

\section{Incompatible materials}

Given that different materials, such as timber and masonry, have different thermal movement characteristics there are risks that where materials are combined, differential movement can result in cracking to finishes. This can be seen typically at the joints of plasterboard and timber partitions where they meet solid masonry walls.

\section{Defective workmanship}

Poor workmanship of course can account for a wide range of damage in a property. This could affect structural elements such as foundations, ground slabs or load-bearing walls.

\section{Wear and tear}

Given that the UK housing stock has a considerable volume of Georgian, Victorian, Edwardian, inter-war and post-war properties that, when built, might only have been designed with a 50-100 year lifespan, 
it is not surprising that defects appear due to gradual deterioration of a building's fabric. It is also relevant to remember that insurance policies are not maintenance contracts and the cost of maintenance is a burden few householders fully take into account when an older property is bought.

There are numerous uninsured reasons for external cracking appearing.

- Wall-tie failure: corroding metal wall ties exert considerable expansive forces on the masonry joints into which they have been built. These forces can blow the bed joints apart and cause horizontal fractures.

- Render cracks: sand and cement render coats vary enormously in quality and over a period of time can become porous, or lose their bond, cracking as a result.

- Lintels: timber lintels situated over windows and door openings can rot and lose strength, or if under-sized can deflect to cause cracking in supported masonry panels. Metal lintels can corrode and fracture masonry.

- Buried timber: many older houses have buried timber wall plates to provide bedding plates for joists and flexibility to large panels of solid brickwork. Over time these timbers can rot or decay making the adjacent masonry overstressed or unstable, causing cracking.

- Sulphate attacks concrete slabs and foundations, and flue gases attack chimney linings.

\section{Not all cracking is structurally significant}

\section{HOW IS SUBSIDENCE DAMAGE RECOGNISED?}

The ISE (2000) has published two tables to assist surveyors in the appraisal of visible damage to buildings. One of the tables (6.1) refers to the potential seriousness of structural cracking and the second (6.2) categorises types of repair. These classification tables are an important point of reference for surveyors and engineers and are based upon work carried out by the Building Research Establishment (BRE) and published in their Digest 251 Assessment of Damage in Low Rise Buildings (BRE, 1995).

The ISE tables categorise damage into six groups (0-5), reflecting crack widths ranging from $<0.1 \mathrm{~mm}$ to $>25 \mathrm{~mm}$ and descriptive definitions ranging from 'hairline' to 'very severe' (see Figure 4). But in addition to this simple classification the surveyor has to take other factors into account when evaluating the significance of cracking.

- Whether the cracks are stable, or progressively worsening.

- The location, size, shape and direction of the cracks and whether they affect the structural stability of the building.

- The extent of cracking in the overall building and whether in total they affect the serviceability of the building.

- The likely cause of the damage. 


\section{Systematic site investigations are essential}

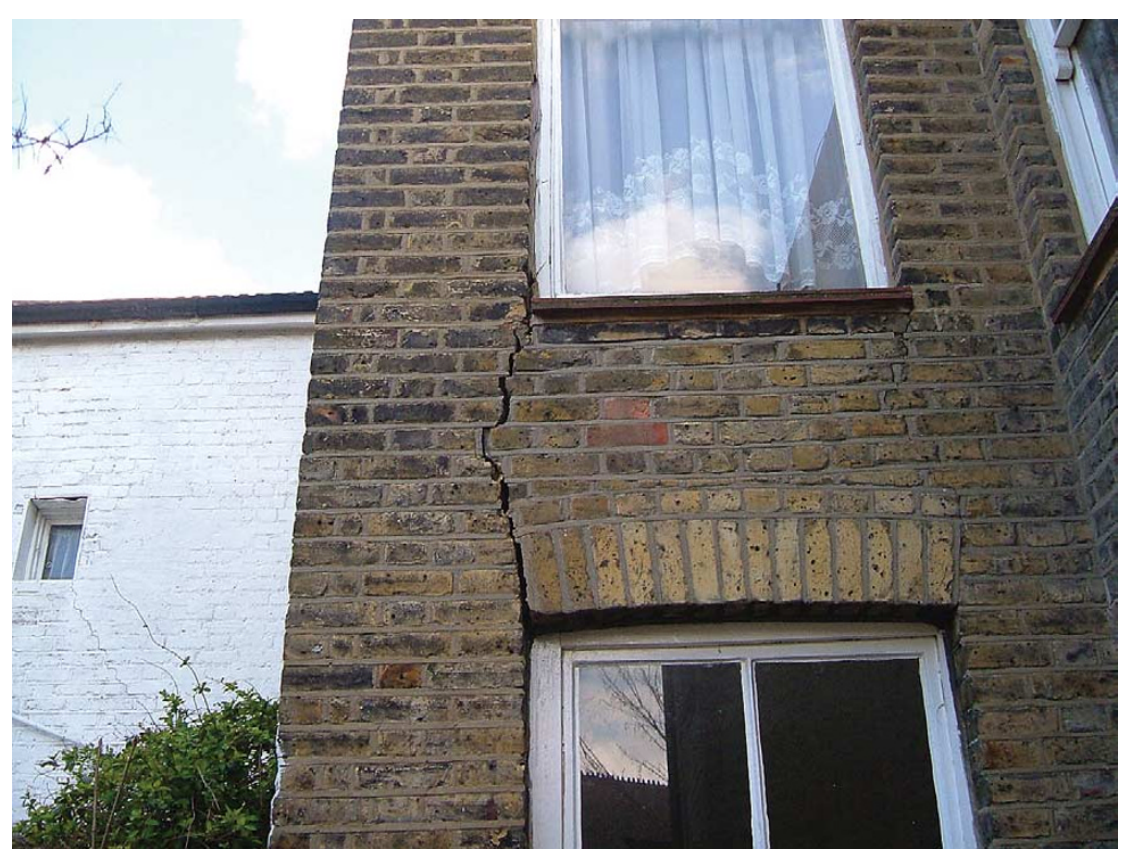

Figure 4: Subsidence fracture - lateral movement of flankwall

\section{SITE INVESTIGATIONS}

The majority of site investigations for domestic subsidence claims follow a routine process of data gathering and elimination of possible causes.

\section{The initial visit}

The initial appraisal (or preliminary) visit to the property is of utmost importance. Not only is it an opportunity to inspect the structure and its locality closely, but also it is time to spend with the property owner to establish the history of the damage and, hopefully, establish some rapport to enable the outcome of the visit to be managed.

Before the visit it can be very worthwhile to review geological drift maps and ordnance survey maps to establish likely ground conditions and the presence of any adverse topographical features (such as mines, watercourses, old quarries etc). The name of local streets can be helpful (it is surprising how many claims are recorded in streets such as Quarry Place or Elmwood Close!).

Because of recent improvements in data management and aerial mapping, many organisations can call up geological and site investigation data simply by typing a postcode into an appropriate search engine.

While the exact procedure of the site visit often can be a matter of personal preference there are a few key rules:

- Allow adequate time for the visit, typically even a modest property may require an hour and a half on site.

- Be methodical in the inspection of the building, inspecting room by room and elevation by elevation, outbuildings and drainage systems 
and recording all visible damage. Measured layout plans annotated with observations are vital.

- Basic surveying equipment to use includes a $1 \mathrm{~m}$ spirit level, $5 \mathrm{~m}$ tape, torch and good-sized screwdriver for discrete prising and prodding of finishes.

- Loft access is desirable (remember to take a ladder) as the arrangement of timbers in a cut roof and the condition of purlins and beams may be directly relevant to a cause of cracking. Many surprises can be revealed in a loft space, including purlins cut through to provide a rooflight, unsupported chimney breasts miraculously hanging off a gable wall or major historic fractures in a party wall that have been covered over below ceiling level.

\section{Further investigations}

\section{CCTV Surveys need to be adjacent to the area of damage}

\section{Tree surveys require expert arboricultural advice}

\author{
Not all cases require \\ complex soils analysis
}

\section{Drainage surveys}

Given the high percentage of drain-related subsidence cases a CCTV survey of underground drains situated within, say, $3 \mathrm{~m}$ of the damaged part of the property is usually required. Correct interpretation of CCTV survey reports is important as minor cracking and slight joint displacement may not be significant compared to major fractures, open joints or collapse (ABI and WRC, 2003).

\section{Arboricultural report}

The earlier part of this paper highlighted the complex issues associated with trees as a cause of subsidence. While building surveyors and engineers are the right people to appraise the building damage, an arboriculturist is recommended for appraising the condition and influence of trees and vegetation. The arboriculturist's role also should extend to organising the removal of a tree if a tree preservation order is in place or arranging for tree surgery works to be carried out safely by a competent contractor. The arboriculturist will work closely with the engineer where a heave risk exists to ensure that removal of a tree will not pose a threat to adjacent properties.

\section{Ground investigation}

Ground investigation (GI) can be a significant part of the claim cost and a great deal of thought is required from the engineer as to the appropriate level required. The majority of cases have easily identifiable causes and require only a basic degree of geotechnical investigation to establish the ground conditions directly beneath the footing adjacent to the damaged area. This may limit the GI to two or three hand-dug holes down to $500 \mathrm{~mm}$ below the footing level and hand augering up to $3 \mathrm{~m}$ in depth. This basic investigation will confirm the expected drift geology and visibly identify adverse local conditions such as fill, softening due to drain leaks and local desiccation due to tree roots. 


\section{Monitoring is required in selected cases only}

\section{Mitigation of tree and drain problems will stabilise most damage}

In more complex cases, deep window sampling or deeper augered holes may be justified together with a regime of soil testing (such as soil suction tests) to establish deep desiccation profiles and the levels of safe-bearing strata, as well as generating data to assist the design of stabilisation schemes.

\section{STABILISING THE BUILDING - MITIGATION WORKS}

Mitigation is now a well-recognised phase of the process, describing actions required to 'mitigate' ongoing movement and damage, or avoiding expensive remedial action such as underpinning. The two obvious mitigation activities are drainage repairs or tree removal. There has been much criticism of lengthy, open-ended monitoring regimes, which have extended claim lives unnecessarily. It is now generally the case that simple drain and tree-related cases will move straight to building repair after mitigation without monitoring.

Where monitoring is required this is generally done using Demec studs and digital callipers recording the crack width. Plastic telltales such as 'Avonguard' calibrated telltales also can be effective. The main application of monitoring is therefore in cases where the cause of damage is not readily identified or capable of mitigation and there is evidence of progressive movement (on made ground, for example).

\section{REPAIRING THE BUILDING}

\section{Superstructure repairs}

The repair phase represents the major part of the claim cost and is the 'moment of truth' for the customer when the property is restored to its preincident state. As noted above, the ISE guide gives an effective categorisation of visible damage to buildings, the type of repair and rectification considerations (ISE, 2000). This categorisation ranges from superficial filling and decoration of hairline cracks to demolition and rebuilding associated with severe damage.

Crack repair techniques have evolved over the years from cumbersome brick stitching using concrete lintels and steel plates to the use of epoxy mortars, helical steel pins and bed joint reinforcement.

\section{Substructure work}

Underpinning is a solution required in less than 5 per cent of cases and is generally the choice of last resort to stabilise the property where

\section{Underpinning is required in a few cases} mitigation cannot be achieved. Localised traditional underpinning can be simple and effective to deepen footings where there is a pocket of poor ground or a local influence on ground conditions such as a mature tree that cannot be removed.

The use of mini-piling techniques using small diameter, steel casings driven into the ground and filled with reinforced concrete is a flexible, economic solution and the piles can be protected against heave in clay soils. Major piling schemes such as the construction of a piled raft to stabilise an entire building footprint can run into tens of thousands of pounds. 
Specialist companies also provide other stabilisation methods, such as Uretek injection grouting and Van Elle Hoopsafe.

\section{CASE STUDY 1 - MANAGING TREE RISK}

Management of trees is a cost effective solution
A typical, inter-war, semi-detached house had suffered minor cracking to internal and external walls due to clay shrinkage. The scope of the investigation included trial holes to establish foundation levels and subsoil condition together with an arboriculturist's report.

Soil tests confirmed the building was founded at $900 \mathrm{~mm}$ below ground level on clay with a PI ranging from 37 to 46 (medium to high shrinkage potential). Roots of all the tree species of up to $5 \mathrm{~mm}$ in diameter were found beneath the foundations.

The arboriculturist identified two trees implicated in the damage: a $6 \mathrm{~m}$-high cherry tree situated $2.5 \mathrm{~m}$ from the building in a neighbour's garden and an $8 \mathrm{~m}$-high group of ash and sycamore situated $1.2 \mathrm{~m}$ from the property belonging to the local authority. Figure 5 illustrates the trees' situation close to the house.

After negotiations with the local authority, trees were removed and remedial works were limited to simple superstructure repairs. Tree removal saved an estimated $£ 10,000$ in underpinning costs.

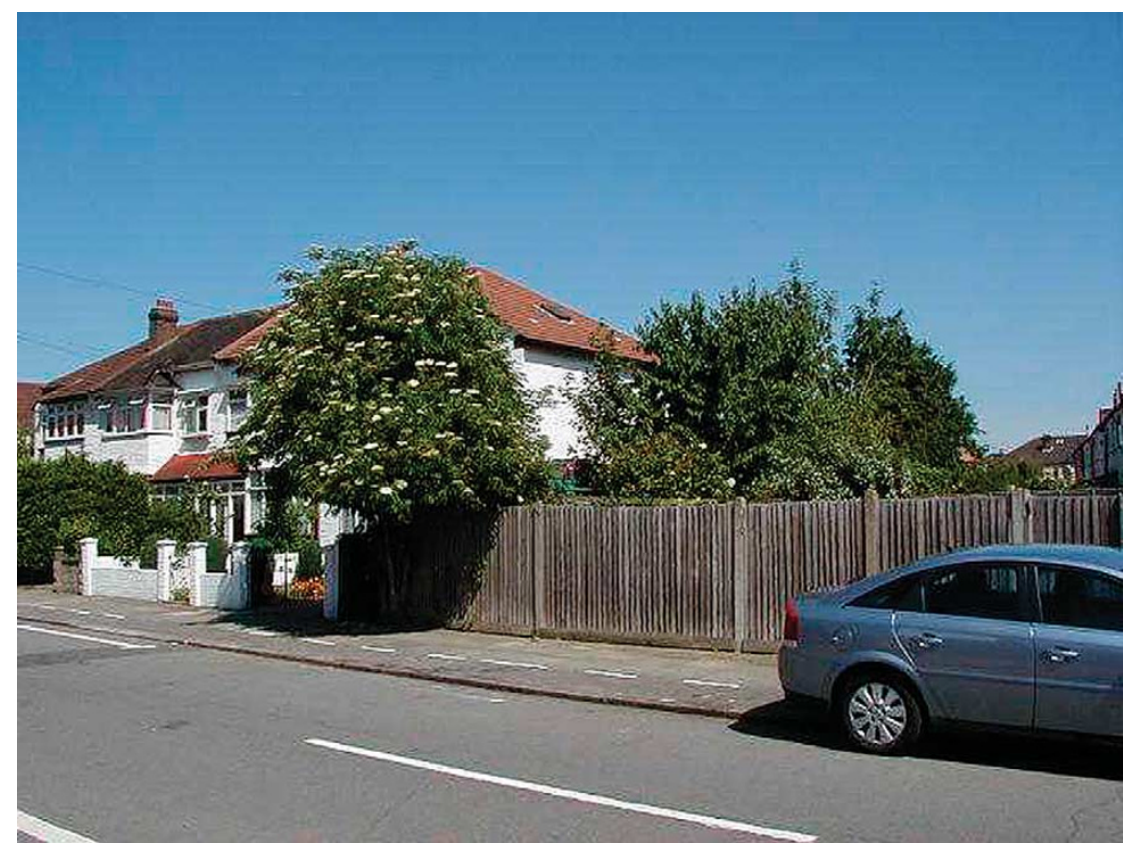

Figure 5: Case Study I - Front elevation photograph

\section{CASE STUDY 2 - MASONRY REINFORCEMENT}

A 1930s detached house situated in a rural setting adjacent to a wood in Wiltshire suffered severe subsidence damage due to clay shrinkage with cracks exceeding $20 \mathrm{~mm}$. Figure 6 shows the front elevation of the property. Site investigations included trial holes, drainage tests and an arboricultural report. Soils were found to have high shrinkage potential. 


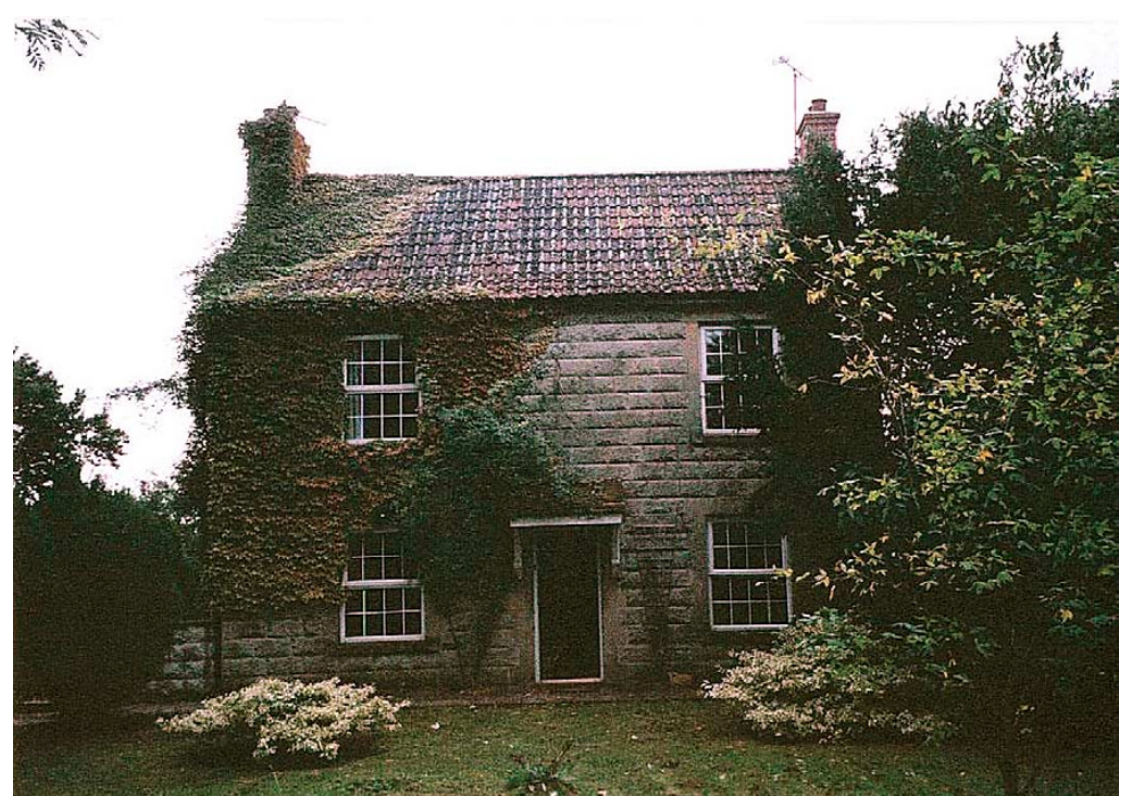

Figure 6: Case Study 2 - Front elevation photograph

Figure 7 shows that the property had a large number of trees within the site boundary and in an adjacent area of woodland. Many of the trees were older than the property and a heave assessment indicated their removal presented a degree of heave risk. There were a number of options to stabilise the building:

- Provide a heave-protected, piled raft foundation to the main house.

- Install a root barrier between the main house and the woodland area.

- Remove vegetation in the immediate vicinity of the house and carry out structural masonry beam reinforcement to the property.

Masonry reinforcement can be effective

\section{Neighbours can be legally liable for tree damage}

The third option was evaluated as the preferred solution and repairs were completed in early 2003. Unfortunately, during the very hot summer of 2003 further slight cracking occurred. A second review by the arboriculturist recommended that the large Turkey oak in the neighbouring woodland be removed. This was successfully negotiated with the landowner and minor additional repairs were carried out. This case demonstrates that tree mitigation and engineered masonry reinforcement schemes provide an effective alternative to a costly piled raft construction.

\section{LEGAL LIABILITY FOR SUBSIDENCE DAMAGE}

Many legal liabilities exist for subsidence damage caused by trees. These liabilities arise in the form of nuisance or negligence of a tree owner's responsibilities to ensure that tree roots do not encroach and damage a neighbour's property. Where damage is shown to have occurred due to the tree a recovery action may be pursued. Domestic tree owners 


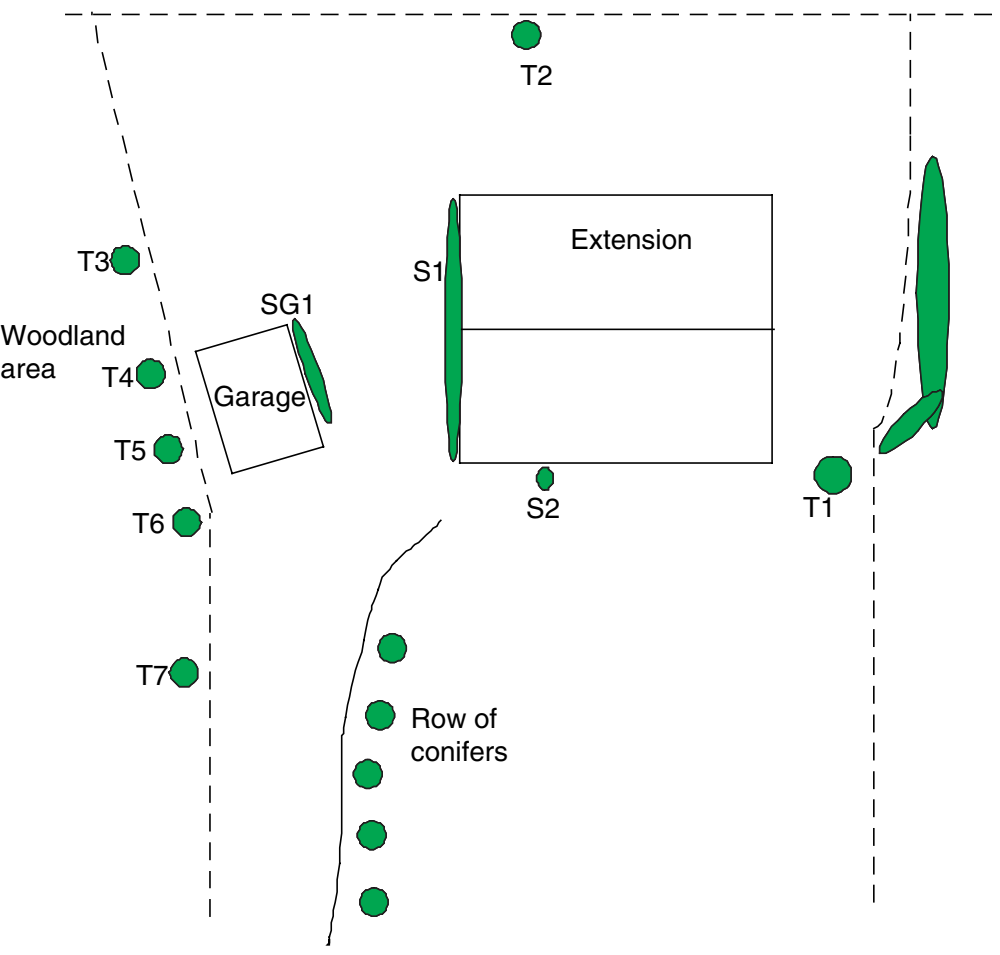

\begin{tabular}{|c|c|c|c|c|}
\hline $\begin{array}{l}\text { Tree } \\
\text { no. }\end{array}$ & Species & $\begin{array}{l}\text { Approx. height } \\
(\mathrm{m})\end{array}$ & $\begin{array}{l}\text { Crown spread } \\
(\mathrm{m})\end{array}$ & $\begin{array}{l}\text { Distance to } \\
\text { building }(\mathrm{m})\end{array}$ \\
\hline $\mathrm{T} 1$ & $\begin{array}{l}\text { Yew } \\
\text { Taxus baccata }\end{array}$ & 5.0 & 6.0 & 2.0 \\
\hline T2 & $\begin{array}{l}\text { Beech } \\
\text { Fagus sylvatica }\end{array}$ & 17.0 & 8.0 & 17.0 \\
\hline T3 & $\begin{array}{l}\text { Oak (Turkey) } \\
\text { Quercus cerris }\end{array}$ & 23.0 & 12.0 & $\begin{array}{r}\text { Garage: } \\
3.5\end{array}$ \\
\hline $\mathrm{T} 4$ & $\begin{array}{l}\text { Yew } \\
\text { Taxus baccata }\end{array}$ & 3.0 & 6.0 & 3.0 \\
\hline T5 & $\begin{array}{l}\text { Lime } \\
\text { Tilia spp. }\end{array}$ & 6.0 & 8.0 & 1.0 \\
\hline T6 & $\begin{array}{l}\text { Sycamore } \\
\text { Acer pseudoplatanus }\end{array}$ & 7.0 & $\begin{array}{r}6.0(\mathrm{G}) \\
10.5(\mathrm{H})\end{array}$ & 6.0 \\
\hline T7 & $\begin{array}{l}\text { Ash } \\
\text { Fraxinus excelsior }\end{array}$ & 18.0 & 9.0 & 13.0 \\
\hline S1 & $\begin{array}{l}\text { Virginia creeper } \\
\text { Parthenocissus quinquefolia }\end{array}$ & 6.0 & 17.0 & 0.5 \\
\hline S2 & $\begin{array}{l}\text { Rose } \\
\text { Rosa spp. }\end{array}$ & 4.0 & 2.0 & 0.5 \\
\hline $\mathrm{H} 1$ & $\begin{array}{l}\text { Mixed species hedge }(\mathrm{H}) \\
\text { Crataegus monogyna, Ulomus spp. }\end{array}$ & 4.0 & 3.0 & 3.0 \\
\hline SG1 & $\begin{array}{l}\text { Mixed species group }(\mathrm{H}) \\
\text { Hebe spp., Pyracantha spp. }\end{array}$ & 2.0 & 2.0 & $0.5(G)$ \\
\hline
\end{tabular}

Figure 7: Case Study 2 - Site plan

may avoid liability based on their lack of knowledge and foreseeing damage occurring.

\section{MANAGING HIGH VOLUMES OF CLAIMS}

It is fair to say that up until the 1990s insurers managed their claims on an individual claim by claim basis, relying on the customer's own 
Insurers often use supply chains and in-house engineers

\section{Global warming may generate future claims}

professional advisers to do the running. After the droughts of 1976 and culminating in a sequence of claims 'events' in the 1990s, insurers started looking closely at the process costs of handling high volumes of subsidence claims.

Not only were claim costs increasing unchecked but customer service was deteriorating with excessively lengthy claim lives creating a portfolio of (pre)historic claims dubbed 'Jurassic Park' within R\&SA. One claim in Jurassic Park was found to have been in progress for over 20 years (albeit it had been opened and closed several times). R\&SA's response was to completely reengineer the way in which its subsidence claims were managed. This involved establishing a competent in-house engineering and claims expertise working hand in hand with a carefully selected and managed supply chain, resulting in leaner processes.

\section{CLIMATE CHANGE - SUBSIDENCE EVENTS AND FUTURE RISK}

In 2004 the ABI published a report evaluating the potential impact of climate change on the insurance industry. As far as subsidence damage in the UK is concerned, an increase in global temperatures and the incidence of hot dry summers suggests an increasing number of claims notifications over the coming decades. The industry is rising to the challenge by looking at technical innovations to continually improve process time and cost. Key areas of innovation include:

- Usage of aerial mapping and laser imaging techniques to improve risk management of properties situated adjacent to urban trees.

- Soils databases to reduce the need for expensive ground investigations.

- Remote monitoring using telemetry to reduce site attendance.

\section{CONCLUSIONS}

Houses have always cracked and, despite improvements in building design and construction, it must be assumed that they will continue to do so. The presence of a crack in a house is a source of potential anxiety for the householder and financial liability for the insurer. Not all cracks are significant or related to subsidence.

Over the past five years there have been major changes in the way insurers, loss adjusters, surveyors and engineers manage subsidence claims and closer working relationships between the numerous parties involved in the process have benefited everyone. Improved knowledge and use of captured data have enabled greater understanding of key process stages, claim timelines and cost drivers. Engineers and surveyors have risen to the challenge and applied their considerable project management and customer skills alongside their technical knowledge to reduce claim costs and claim lives, while still maintaining a professional approach and customer focus. Increasing risks associated with climate change over the next 40 years no doubt will continue to challenge building professionals to improve and innovate further. 


\section{References}

Association of British Insurers (ABI) (2004) Association of British Insurers (ABI), A Changing Climate for Insurers, Datamonitor, June.

Association of British Insurers (ABI) and Water Research Council (WRC), (2003). Drain Repair Book. Best Practice Manual for the Inspection and Repair of Domestic and Light Industrial Drains, WRC, Swindon.

Building Research Establishment (BRE), (1995) BRE Digest 251: Assessment of Damage in Low Rise Buildings with Particular Reference to Progressive Foundation Movement, BRE, Watford.

Datamonitor (2004) UK Household Insurance 2004/2005, Datamonitor.

Institution of Structural Engineers (ISE), (2000). Subsidence to Low-Rise Buildings, 2nd edn, SETO, London.

Royal and Sun Alliance (R\&SA), (2004). Choices Insurance Policy, R\&SA, Horsham.

\section{Further reading}

Biddle, P. G., (1998). Tree Root Damage to Buildings, Willowmead, Wantage.

Freeman, T. J., Littlejohn, G. S., Driscoll, R. M. C., (2001). Has Your House Got Cracks?, Thomas Telford, London.

NHBC, (2000). Buildings Near Trees Standards, Chapter 4.2, NHBC, Amersham.

Royal and Sun Alliance, (2003). The Subsidence Handbook, R\&SA, Horsham.

\section{LEGAL CASE REFERENCES}

Loftus-Brigham v Ealing Borough Council (2003) EWCA Civ 1490. Delaware Mansions Ltd v City of Westminster (1999) 1 AC 321 (31). Paterson v Humberside County Council (1995) Const LJ 64.

Greenwood v Portwood (1984) CLY 2500. 